\title{
Interactive effects of nutritional condition and refuge availability on survival of a temperate reef goby
}

\author{
Emily Y. Floyd ${ }^{1,2,3, *}$, Todd W. Anderson ${ }^{1}$ \\ ${ }^{1}$ Department of Biology and Coastal and Marine Institute, San Diego State University, 5500 Campanile Drive, San Diego, \\ California 92182, USA \\ ${ }^{2}$ Graduate Group in Ecology, 2148 Wickson Hall, University of California, Davis, California 95616, USA \\ ${ }^{3}$ Present address: ENTRIX Inc., 2300 Clayton Road, Suite 200, Concord, California 94520, USA
}

\begin{abstract}
Variation in individual performance and condition of marine organisms can influence larval supply and the outcome of post-settlement processes. The broad applicability of these patterns among systems and under different environmental conditions, however, remains relatively unknown. We determined whether nutritional condition would affect the survival of recently settled recruits of a temperate reef fish, the blackeye goby, and whether refuge availability would modify the importance of condition. Recruits were fed high or low food rations in the laboratory for $15 \mathrm{~d}$, after which pairs of high- and low-ration fish were marked and placed on standardized plots of rock rubble in the field. Plots were monitored daily to determine mortality over $12 \mathrm{~d}$. To examine the combined effects of condition and refuge availability, pairs of fish were placed on plots of high, medium, or low amounts of refuge. Laboratory experiments examined the effect of condition on burst swimming speed to elucidate the mechanisms underlying the observed patterns of survival. On standardized plots, fish fed low rations experienced higher mortality than fish fed high rations. When refuge was manipulated, low-ration fish experienced higher mortality than high-ration fish at higher levels of refuge. Surprisingly, higher mortality was observed for high-ration fish on low-refuge plots, possibly due to differences in risk-prone behavior. A reduction in the overall probability of mortality resulted in an unanticipated dampening of the importance of condition for survival. Our results indicate that the ecology of individuals, mediated by environmental conditions, is an important constituent in the population demography of reef fishes.
\end{abstract}

KEY WORDS: Fishes · Energy reserves $\cdot$ Lipid $\cdot$ Habitat $\cdot$ Population demography $\cdot$ Rocky reefs

\section{INTRODUCTION}

The physiological state, or condition, of marine organisms appears to vary greatly through space and time due to variability in environmental conditions such as temperature and food supply (McCormick \& Molony 1993, Kerrigan 1996, Hentschel \& Emlet 2000), and this variation may have significant demographic consequences. Elevated nutritional condition, for example, has positive implications for survival of seabirds (Perez et al. 2006), growth in barnacles (Thiyagarajan et al. 2005), and swimming endurance (Stobutzki 1997), offspring quality (McCormick 2003), and sur- vival (Booth \& Hixon 1999) in fishes. Moreover, the relationships between nutritional condition and reproduction, growth, and survival vary depending on environmental conditions (Thiyagarajan et al. 2005, Sponaugle \& Grorud-Colvert 2006, Gagliano et al. 2007, Figueira et al. 2008, Hamilton 2008, Hamilton et al. 2008). Considering the variability in environmental conditions and nutritional status observed within and among systems, information about whether and how these 2 factors interact is essential for a better understanding of population dynamics.

The roles of larval supply and subsequent postsettlement processes have been the focus of many 
studies on the population demography of marine fishes (see reviews by Doherty 2002, Hixon \& Webster 2002, Steele \& Anderson 2006), but variation in individual characteristics and performance also play an important role (Booth \& Hixon 1999, Searcy \& Sponaugle 2001, McCormick 2003). More specifically, the quality of planktonic larvae can mediate the number and condition of recently settled fish in benthic habitats, thereby affecting the outcome of post-settlement processes. For fish in better condition, the mechanisms responsible for these effects include reduced starvation (Berkeley et al. 2004), lower predation risk due to reduced risktaking behavior or improved swimming abilities (Kieffer \& Tufts 1998, Martinez et al. 2004, Skajaa et al. 2004), and an enhanced ability to compete for limiting resources (Booth \& Beretta 2004).

Because swimming ability is critical for predator avoidance and is often linked with feeding history, it is an important factor to consider when evaluating the mechanisms responsible for differential survival based on energy reserves. Food restriction has been shown to have a number of biochemical (e.g. ATP-producing enzyme activity, Martinez et al. 2004) and physiological (e.g. muscle development, McCormick \& Molony 1992, Martinez et al. 2004; energy reserves, McCormick \& Kerrigan 1996, Booth \& Hixon 1999) effects in fish, which could potentially influence swimming metabolism and performance. Negative effects of food restriction on swimming performance have been observed in a variety of species (Yin \& Blaxter 1987, Stobutzki 1997, Chick \& Van Den Avyle 2000, Martinez et al. 2004), likely due to deficiencies in major carbohydrate fuels such as plasma glucose and liver and muscle glycogen that can occur when fish are unable to acquire adequate nutrition (Kieffer \& Tufts 1998, Sherwani \& Parwez 2000).

Although it may seem intuitive that individuals with higher stored energy reserves would exhibit improved survival relative to those in poor condition, this is not always the case (McCormick \& Kerrigan 1996), and it is possible that differences in environmental conditions may explain some of these discrepancies. Despite growing interest in the implications of individual condition for the population ecology of fishes, how condition may interact with other environmental factors that determine the growth and survival of early life stages (Sponaugle \& Grorud-Colvert 2006, Gagliano et al. 2007, Figueira et al. 2008, Hamilton 2008, Hamilton et al. 2008) remains poorly understood. Moreover, recent field studies demonstrating the importance of nutritional condition and growth for survival of larval and juvenile fishes have been conducted mainly in tropical reef systems (Searcy \& Sponaugle 2001, McCormick 2003, Hoey \& McCormick 2004), whereas similar studies of temperate reef fishes remain largely unexplored (but see Yin \& Blaxter 1987, Cushing 1990, Shima \& Findlay 2002, Beaugrand et al. 2003 for discussion of laboratory, observational, and correlative approaches).

Our objectives were to determine (1) the individual and combined effects of nutritional condition and refuge availability (habitat structure) on survival of recent recruits of the blackeye goby Rhinogobiops nicholsii (family Gobiidae), and (2) the effect of feeding regime and thus condition on burst swimming speed as a mechanism for greater survival of recently settled individuals. We used a series of experiments to address the following specific hypotheses: (1) fish in 'poor' condition will experience higher mortality when exposed to predators in the field than those in relatively 'good' condition, (2) the importance of nutritional condition for survival will vary depending on refuge availability, and (3) burst swimming speed will reflect greater energy reserves in fish as a mechanism for higher survival of high-condition gobies in the field. We selected refuge availability as an additional factor because of its demonstrated importance for the survival of temperate reef fishes (Steele 1999, Anderson 2001, Johnson 2007), and the relatively limited understanding of how condition may interact with other factors to determine survival (but see Johnson 2008). We expected that condition would be important for survival at intermediate to higher levels of refuge availability, but not at low levels because fish would be vulnerable to predators regardless of nutritional status.

\section{MATERIALS AND METHODS}

Species and study area. The present study was conducted at Santa Catalina Island ( $\left.33^{\circ} 27^{\prime} \mathrm{N}, 118^{\circ} 29^{\prime} \mathrm{W}\right)$, $40 \mathrm{~km}$ offshore of southern California, USA. All field experiments were conducted within Big Fisherman Cove (BFC) along an area of sandy bottom adjacent to a continuous kelp-forested reef. We used recently settled recruits of the blackeye goby to evaluate the roles of condition and refuge availability in determining survival. Blackeye gobies are sedentary, spending most of their time resting on rocks or sand, foraging for zooplankton and benthic invertebrates. Larvae of this species typically settle to benthic habitat at a size of 15 to $25 \mathrm{~mm}$ standard length (SL) (Steele 1999). At Santa Catalina Island, the primary predator of the blackeye goby is the kelp bass Paralabrax clathratus (family Serranidae), accounting for $>90 \%$ of all piscivorous predators in this area (Steele 1999).

Fish collection and feeding trials. Recruits of the blackeye goby (22 to $27 \mathrm{~mm}$ total length [TL], likely within $2 \mathrm{wk}$ post-settlement) were collected at Lion Head Reef $(\sim 1 \mathrm{~km}$ from BFC) using small hand nets and transferred underwater into individual plastic 
bags. After collection, fish were transported to the laboratory at the Wrigley Marine Science Center for feeding trials. All fish were weighed (to the nearest $0.001 \mathrm{~g}$ ), measured (SL and TL), and allocated to feeding treatments.

We assigned fish randomly to high-ration (20\% initial body wt $\mathrm{d}^{-1}$ ) and low-ration (3.3\% initial body wt $\mathrm{d}^{-1}$ ) treatments, similar to the rations used in previous studies (Booth \& Hixon 1999) and in a pilot study we conducted in 2002. The pilot study indicated that a $3.3 \%$ body weight feeding treatment was a maintenance ration, whereas a $20 \%$ body weight feeding treatment was sufficient to cause significant increases in growth and condition (i.e. Fulton's condition factor, $K$, E. Y. Floyd unpubl. data) in recruits of the blackeye goby. The food rations consisted of a mixture of frozen brine and mysid shrimp (San Francisco Bay Brand), which were defrosted prior to feeding. Extra moisture was removed from the defrosted shrimp before food rations were weighed. In 2002, fish were held individually in $10 \times 10 \mathrm{~cm}(1.2 \mathrm{l})$ plastic compartments within a matrix of 16 compartments. One row of 4 compartments was left unoccupied and used for seawater input to reduce any stress caused by turbulence from inflowing water. Three matrices were used for a total of 36 compartments. In 2003 to 2005, fish were held in the 1.21 compartments and in thirty-two 41 plastic containers to allow for additional replication for field experiments. Although the 2 types of containers differed in size, gobies in the larger containers rarely utilized the additional space (i.e. they were primarily stationary on the bottom as were gobies in the smaller containers), and no differences in effect of feeding treatment on condition were observed between container types. All individual compartments and containers were supplied with flow-through seawater for the duration of a $15 \mathrm{~d}$ feeding period. Prior to their final feeding on Day 15 , fish that were used in subsequent field experiments were re-weighed and re-measured, and then marked with different colors of elastomer (Malone et al. 1999) so that high- and low-ration fish, and fish placed on different plots, could be distinguished in the field. Importantly, experimental fish were also marked so that losses due to emigration could be distinguished from predation.

In 2005, a feeding experiment was conducted using the procedures described in the previous paragraph to sample fish for lipid content analysis. The purpose of this experiment was to verify that distinct condition levels were established during prior feeding trials. At the end of the $15 \mathrm{~d}$ feeding period, fish were euthanized using tricaine methanesulfonate (MS-222) and frozen at $-80^{\circ} \mathrm{C}$. Frozen fish were transported to San Diego State University (SDSU) on dry ice and again stored in $\mathrm{a}-80^{\circ} \mathrm{C}$ freezer. Chloroform-methanol lipid extractions were performed at SDSU using methods adapted from Bligh \& Dyer (1959). After total lipid was extracted from each fish, lipid extracts were transported to the Southwest Fisheries Science Center (NOAA Fisheries Service) in Santa Cruz, California, for lipid class analysis. Lipids were separated into steryl or wax ester, triacylglycerol, nonesterified fatty acid, cholesterol, and polar lipid classes on chromarods in a solvent bath consisting of hexane, ethyl ether, and formic acid. Separated peaks were quantified using thin-layer chromatography with flame ionization detection (TLC-FID) by an Iatroscan TH-10 Mark III (MacFarlane et al. 1993), and by comparing peak areas to external standard curves for each lipid class (MacFarlane \& Norton 1999). Our analyses focused on triacylglycerides (TAG) because they are an important source of stored energy reserves for growth, development, and starvation tolerance in larvae and juveniles of other temperate fishes (MacFarlane \& Norton 1999, Berkeley et al. 2004), and likely play a role in determining foraging behavior and predation risk (GrorudColvert \& Sponaugle 2006). Food ration and Fulton's $K$, $K=($ weight, $\mathrm{kg}) \times(\mathrm{TL}, \mathrm{m})^{-3}$, were also used as indicators of nutritional condition.

To assess natural spatial and temporal variability in nutritional condition of recently settled gobies (22 to $27 \mathrm{~mm}$ TL), additional fish were collected in 2005 at 3 sites spanning $\sim 5 \mathrm{~km}$ (Lion Head, Chalk Cliffs, and Emerald Bay) and 3 time points during the summer (June, July, and August). These fish were weighed, measured, and euthanized immediately for calculations of Fulton's $K$ and lipid content analysis.

Expt 1. Effects of condition on survival. The importance of nutritional condition for survival of recently settled recruits of the blackeye goby was assessed from June through September in each of 4 summers (2002 to $2005)$ to achieve adequate replication. Twenty-one experimental plots $\left(0.25 \mathrm{~m}^{2}\right)$ were constructed out of rock rubble on sand bottom in BFC. Rocks used to build these habitats were standardized according to size (size range: 15 to $20 \mathrm{~cm}$ along the longest dimension). Plots were separated from each other and from the adjacent natural reef by at least $10 \mathrm{~m}$ of open sand to ensure independence of experimental units (Steele 1999). Highand low-ration fish were paired according to body length at the end of feeding trials to avoid confounding the effects of condition and size, and each pair was placed on a $0.25 \mathrm{~m}^{2}$ rock rubble plot. Because fish from the 2 ration treatments were paired in the field, the treatments were represented equally during each summer in which the experiment was conducted, and at each plot location. Plots used in this experiment consisted of a single layer of 16 rocks, arranged in a square $\left(4\right.$ rocks side $\left.{ }^{-1}\right)$. Pairs of marked fish were released onto plots enclosed by a predator-exclusion cage 
$(1 \mathrm{~m} \times 1 \mathrm{~m} \times 0.65 \mathrm{~m}$ PVC cage covered with $3 \mathrm{~mm}$ plastic mesh) for a $24 \mathrm{~h}$ acclimation period, after which cages were removed and the experiment was initiated. Only plots in which both high- and low-ration fish were present after the acclimation period were used in this experiment $(\mathrm{n}=66$ total per treatment: $\mathrm{n}=15$ in 2002, $\mathrm{n}=9$ in 2003, $\mathrm{n}=32$ in 2004, and $\mathrm{n}=10$ in 2005) to ensure that any losses observed were due to mortality and not emigration caused by handling effects. Plots were monitored daily to determine mortality over $12 \mathrm{~d}$. After $12 \mathrm{~d}$, fish remaining on plots were weighed, measured, and euthanized so we could determine Fulton's $K$ and lipid content of individuals in each ration treatment.

Expt 2. Interactive effects of condition and refuge availability. An experiment to assess the individual and combined effects of condition and refuge availability on survival of the blackeye goby was conducted from June through September in each of 2 summers (2004 and 2005) to achieve adequate replication. Rock rubble plots $\left(0.25 \mathrm{~m}^{2}\right)$ were manipulated in the field to create 3 levels of refuge availability (low: 8 rocks plot $^{-1}$, medium: 16 rocks plot ${ }^{-1}$, and high: 24 rocks plot $^{-1}$ ), and pairs of high- and low-ration fish were placed on each plot as in Expt 1, for which only replicates where both fish were present after the acclimation period were employed $(\mathrm{n}=22$ total for low-refuge treatment: $\mathrm{n}=11$ in 2004 and $\mathrm{n}=11$ in 2005; $\mathrm{n}=21$ total for medium-refuge treatment: $\mathrm{n}=11$ in 2004 and $\mathrm{n}=10$ in $2005 ; \mathrm{n}=21$ total for high-refuge treatment: $\mathrm{n}=10$ in 2004 and $\mathrm{n}=11$ in 2005).

Rocks used to build these habitats were standardized according to size (size range: 15 to $20 \mathrm{~cm}$ along the longest dimension). Each refuge treatment was constructed so as to cover the same areal extent $\left(0.25 \mathrm{~m}^{2}\right)$. Within this area, the medium-refuge plots consisted of 16 rocks in a single layer (identical to plots used in Expt 1), the high-refuge plot included an additional 8 rocks in a second layer, and the low-refuge plots consisted of a medium-refuge plot which had been 'thinned' by removing 8 rocks in a haphazard manner. These refuge levels were chosen based on the levels of refuge availability observed in areas of the sand-rock rubble interface where we commonly observed blackeye gobies in their natural habitat (E. Y. Floyd pers. obs.). The extent of usable habitat would necessarily differ among these refuge treatments. However, we do not believe density dependence confounded the effects of condition and refuge in this case because only 2 fish were placed on each plot, any settlers were removed each day, and refuge did not appear to be a limiting factor for any of our 3 refuge levels (i.e. both fish were able to, and often did, take shelter simultaneously, even on low-refuge plots).

By pairing high- and low-ration fish on each plot, and using a randomized block design, we controlled for any extrinsic factors that could introduce bias (e.g. predator densities). Plots were monitored daily to determine survival over $12 \mathrm{~d}$. Any fish remaining at the end of $12 \mathrm{~d}$ were collected and euthanized for calculations of Fulton's $K$ and lipid content analysis. Surveys of the experimental plots and adjacent reef were conducted concurrently with Expts 1 and 2 to search for marked emigrants and quantify levels of emigration versus predator-induced mortality. We surveyed the adjacent reef for emigrants periodically during 2004 and 2005, for a total of $5 \mathrm{~h}$ survey time. The experimental plots were surveyed daily for emigrants during surveys conducted to evaluate mortality rates.

Expt 3. Effects of condition on burst swimming speed. The effect of condition on burst swimming speed was evaluated from June through September 2002. Maximum burst swimming speeds were measured in high-ration $(n=27)$ and low-ration $(n=29)$ fish after their final feeding on Day 15 of the feeding period. Burst swimming speeds were measured in a long, narrow test chamber $(50 \times 1.2 \times 13 \mathrm{~cm})$, which limited side-to-side movement during swimming trials. The back of the aquarium was made of opaque, white plexiglass for easier visibility of the fish by the observer, and the sides and front of the aquarium were clear, allowing experimental trials to be filmed with a video camera. A $15 \mathrm{~cm}$ ruler was attached to the back of the chamber to facilitate calculations of burst swimming speed. Water was exchanged every 3 trials using a flow-through seawater system to maintain good water quality (temperature: $22.2^{\circ} \mathrm{C}$, dissolved oxygen concentration: $8.2 \mathrm{mg} \mathrm{l}^{-1}$ ).

For each trial, individual fish were placed in the aquarium and allowed a 3 min acclimation period before we conducted a swimming trial. After acclimation, a tactile stimulus was applied to the caudal peduncle using a dissecting probe to elicit a burst swimming escape response. Fish were prodded until a number of bursts were recorded. Fish that never performed a true burst response were deemed 'non-responsive' and were excluded from subsequent analyses. All burst swimming trials were recorded with a digital video camera (Sony DCR-PC101 Digital Handycam, 60 frames $\mathrm{s}^{-1}$ ), and video analysis was conducted using PEAK 6.1 video analysis software. Using PEAK software, we determined burst swimming speeds for each frame within the entire burst motion for an individual fish. Each burst was analyzed 2 times to minimize any variation based on measurement error. The maximum speeds attained within each burst from these 2 analyses were averaged, and this average was used as the measure of maximum burst swimming speed.

Statistical analyses. We compared Fulton's $K$ of high- and low-ration fish from Expt 1 using 2-way ANOVA, with year and ration as independent vari- 
ables, and Fulton's $K$ as the dependent variable calculated before and after feeding trials and field experiments. We used data from Expt 1 and the mediumrefuge plots used in Expt 2 for these analyses so that we could evaluate whether our feeding treatments established differences in condition without incorporating the effect of refuge availability. Tukey's honestly significant difference (HSD) tests were used to identify significant differences among treatments. All data on lipid content was $\log$ e $(x+1)$-transformed due to heterogeneity of variances. Lipid content of high- and low-ration fish was compared after feeding trials conducted in 2005 with a 2-sample $t$-test. We compared lipid reserves of high- and low-ration fish after the $12 \mathrm{~d}$ field experiment using a 2-way ANOVA, with year and ration as independent variables. Lipid content of fish collected at 3 different sites and 3 time points to assess natural variation in energy reserves ('natural' fish) was compared using a random-effects ANOVA, with sampling date and site as independent variables. Although Levene's test indicated that variances were heterogeneous, and the distribution of 'natural' lipid levels remained somewhat skewed, after log e $(x+1)$ transformation, the ANOVA was likely robust to these violations due to our large sample sizes (minimum $\mathrm{n}=$ 20 per site). To compare lipid content of 'natural' fish to that of the laboratory-fed fish, we matched median TAG levels of high- and low-ration fish to percentiles within the natural range.

To analyze data from Expt 1, we used a non-parametric form of survival analyses, the Kaplan-Meier estimator, and likelihood ratio tests to determine if data collected over 4 summers (2002 to 2005) could be pooled. The Kaplan-Meier estimator is particularly powerful when incidence rates (i.e. mortality rates) do not remain constant over time, and when the time to an event is important (Rosner 2006). This type of analysis compares the probability of survival at each time point among treatments and integrates data for each time point over the entire experimental period, producing a single chi-squared statistic with which to evaluate differences. The probability of survival for each group is calculated using the observed number of events (failures) and the expected number of events, which is based on the total number of fish that are at risk at each time point (Rosner 2006). Because these analyses indicated that patterns of survival were similar among summers $\left(\chi^{2}=1.779, \mathrm{df}=3, \mathrm{p}=0.620\right)$, we pooled the data before using survival analyses to evaluate the effects of nutritional condition on survival. Ranking the 2 ration treatments based on the time to $25 \%$ loss revealed the same rank order of treatments in 3 out of 4 summers (2002 to 2004), further supporting the pooling of data across years. In 2005, there was no significant difference in the time to disappearance of high- and low-ration fish; however, our sample size and thus our power to detect differences between the ration treatments was quite low in this summer for Expt 1. Although we were not able to detect a distinct pattern in 2005, we have included data collected in this year in the analyses as a conservative approach to evaluating the overall importance of ration for survival. The Kaplan-Meier estimator was then used to compare patterns of survival among our 2 ration treatments.

For Expt 2, the Kaplan-Meier estimator and likelihood ratio tests were used to determine whether data collected over 2 summers (2004 and 2005) could be pooled. These analyses showed that there were no 2or 3-way interactions between year and feeding treatment and refuge availability (year $\times$ ration: $\chi^{2}=0.017$, $\mathrm{df}=1, \mathrm{p}=0.896$; year $\times$ refuge: $\chi^{2}=2.312$, $\mathrm{df}=2, \mathrm{p}=$ 0.315 ; year $\times$ ration $\times$ refuge: $\chi^{2}=2.234, \mathrm{df}=2, \mathrm{p}=$ 0.327 ), allowing for pooling of the data. Ranking of each ration-by-refuge treatment based on the proportion of fish surviving to the end of the experiment indicated that the rank order of treatments was the same for each year, further supporting pooling of data collected in 2004 and 2005. Likelihood ratio tests also revealed that patterns of survival observed on mediumand high-refuge plots were not different $\left(\chi^{2}=0.352\right.$, $\mathrm{df}=2, \mathrm{p}=0.839$ ). Due to the relatively limited statistical power of analyses conducted for medium- and high-refuge plots separately, and the similarity between results obtained for these 2 refuge levels, we pooled data collected for these 2 refuge treatments. The Kaplan-Meier estimator and likelihood ratio tests were then used to compare patterns of survival among our 4 treatments (i.e. all combinations of the 2 feeding treatments [low, high] and 2 refuge availability treatments [low, medium/high]).

Due to space limitations within the experimental area, and the importance of maintaining spatial independence among plots, it was necessary to use plots multiple times within a year to achieve adequate replication. Because temporal replication can introduce the potential for bias, we evaluated the survival outcomes on each individual plot, while holding refuge constant, to determine if multiple trials on a single plot were independent. We were unable to assess the independence of plots statistically due to a limited sample size on each individual plot, but our descriptive analysis revealed that survival outcomes generally varied on a single plot. Moreover, there is limited potential for bias in our results with respect to the primary factors of interest, the ration and ration-by-refuge effects, because both ration treatments were represented on each plot. With respect to refuge, there is some potential for bias based on the repeated use of plots because the refuge treatments were not all represented at the same location. However, the effect of refuge on sur- 
vival was strong, and it is unlikely that any potential bias would alter these results significantly. We were able to assess the effect of plot location on overall mortality rates statistically using the Kaplan-Meier estimator, and found no evidence of lack of independence among plots $\left(\right.$ Expt 1: $\chi^{2}=22.9, \mathrm{df}=19, \mathrm{p}=0.242$; Expt 2 low-refuge plot: $\chi^{2}=14.394, \mathrm{df}=11, \mathrm{p}=0.212$; Expt 2 medium/high-refuge plot: $\chi^{2}=21.079$, df $=17, \mathrm{p}=$ 0.223). Consequently, we consider these temporal replicates to be independent of one another for the survival analyses conducted.

Mortality was not observed on a substantial number of plots during both experiments, thereby potentially obscuring significant patterns of survival observed on plots where mortality did occur. At issue is whether predators targeted a plot during a trial. If not, the results of the intended experiment were diluted. If predators targeted the plot but were not able to catch their prey, this lack of predation would be important in the
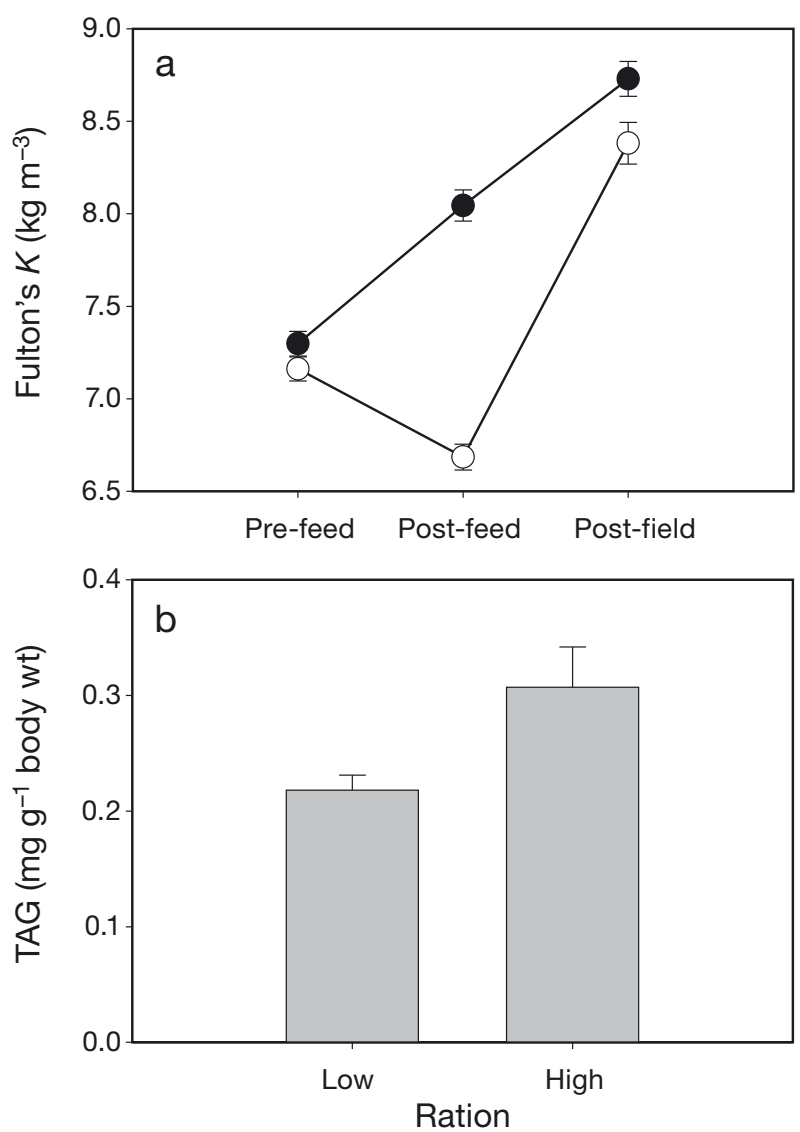

Fig. 1. Rhinogobiops nicholsii. Mean values for (a) Fulton's $K$ for high-ration $(\bullet)$ and low-ration $(O)$ fish calculated before ( $\mathrm{n}=92$ and 93 for high- and low-ration fish, respectively) and after feeding periods ( $\mathrm{n}=93$ per treatment) and after Expt 1 ( $\mathrm{n}=39$ and 29 for high- and low-ration fish, respectively), and for (b) triacylglyceride (TAG) levels after feeding periods ( $\mathrm{n}=13$ and 11 for high- and low-ration fish, respectively). Error bars represent SE context of mortality based on condition. Therefore, we have provided survival analyses for Expts 1 and 2 in 2 ways for overall interpretation: (1) including plots where no mortality occurred during the $12 \mathrm{~d}$ field experiment, and (2) excluding plots where no mortality occurred. In the 'Results', statistics generated from the inclusion of plots where no mortality occurred will be denoted as 'including all plots' and statistics generated from the exclusion of plots where mortality did not occur will be denoted as 'excluding plots'. Although plots in which both fish remained at the end of the $12 \mathrm{~d}$ field experiment do not represent predation events, they do provide important information about overall predation rates in this system, at least under the experimental and environmental conditions applicable to the present study. By comparing the results from these 2 types of analyses, we were able to evaluate how the probability of mortality in a given system may influence the importance of both condition and refuge for survival.

For Expt 3, the relationship between feeding treatment (high- vs. low-ration) and burst swimming speed $\left(\mathrm{cm} \mathrm{s}^{-1}\right)$ was evaluated using analysis of covariance (ANCOVA), with feeding treatment as the main effect and body size (mm SL) as a covariate. Probability plots and Levene's test were used to evaluate the assumptions of normality and homoscedasticity for ANOVA, and data were log e-transformed when necessary.

\section{RESULTS}

\section{Indices of nutritional condition}

\section{Fulton's $K$}

There was no difference between high- and lowration fish with respect to Fulton's $K$ prior to the feeding experiments $\left(F_{1,177}=1.954, p=0.164\right.$, Fig. 1a). After feeding, there was a significant interaction between feeding treatment and year $\left(F_{3,178}=3.823, \mathrm{p}=0.011\right)$ because the magnitude of the difference in condition between high- and low-ration fish varied among years. These differences, however, were always consistent in direction. Fulton's $K$ for high-ration fish was $20 \%$ higher than for low-ration fish on average after feeding (Fig. 1a). Mean values of Fulton's $K$ calculated for high- and low-ration fish at the end of the feeding periods conducted prior to Expts 1 and 2 were within the range of values calculated for 'natural' fish (low-ration: $K=6.69 \pm 0.070 \mathrm{~kg} \mathrm{~m}{ }^{-3}$, high-ration: $K=8.04 \pm$ $0.084 \mathrm{~kg} \mathrm{~m}^{-3}$, natural range: $K=6.17$ to $8.98 \mathrm{~kg} \mathrm{~m}^{-3}$ ), indicating that the feeding treatments used in our experiments were relevant to ambient levels of energy reserves. 
At the completion of Expt 1, Fulton's $K$ for highration fish was only $\sim 4 \%$ higher than that of low-ration fish (mean values for Fulton's $K$ after field experiments: low-ration: $K=8.38 \pm 0.113 \mathrm{~kg} \mathrm{~m}^{-3}$, high-ration: $K=$ $8.73 \pm 0.094 \mathrm{~kg} \mathrm{~m}^{-3} ; F_{1,60}=4.432, \mathrm{p}=0.039$, Fig. 1a), likely due to increases in condition observed in lowration fish during field experiments or possibly greater selection by predators against low-ration fish with the lowest levels of energy reserves.

\section{Lipid content}

TAG content of high-ration fish was $~ 41 \%$ higher than that of low-ration fish after the feeding period $(t=$ $2.301, \mathrm{p}=0.033$; low-ration: TAG content $=0.218 \pm$ $0.013 \mathrm{mg} \mathrm{g}^{-1}$ body wt [n = 11], high-ration: TAG content $=0.307 \pm 0.035 \mathrm{mg} \mathrm{g}^{-1}$ body wt $[\mathrm{n}=13]$, Fig. $1 \mathrm{~b}$ ). The correlation between TAG reserves and Fulton's $K$ was not significant $(r=0.262, p=0.217)$ due to variation in TAG levels within a narrow range of values for Fulton's $K$, but the 2 variables did show similar general responses to higher food rations (Fig. 2). By the end of the field experiments, TAG reserves measured in highand low-ration fish were not different $\left(F_{1,54}=0.775, \mathrm{p}=\right.$ 0.383).

Analyses of natural variation in TAG reserves indicated that TAG levels measured in fish after feeding periods were within the range of values measured for fish collected from nearby reefs, but at the lower end of this range (natural range: $\mathrm{TAG}=0.12$ to $4.56 \mathrm{mg} \mathrm{g}^{-1}$ body wt). Specifically, the lipid levels of low- and highration fish corresponded to the 27th and 39th percentiles of the 'natural' range of lipid values, respectively. When evaluating TAG reserves of fish collected

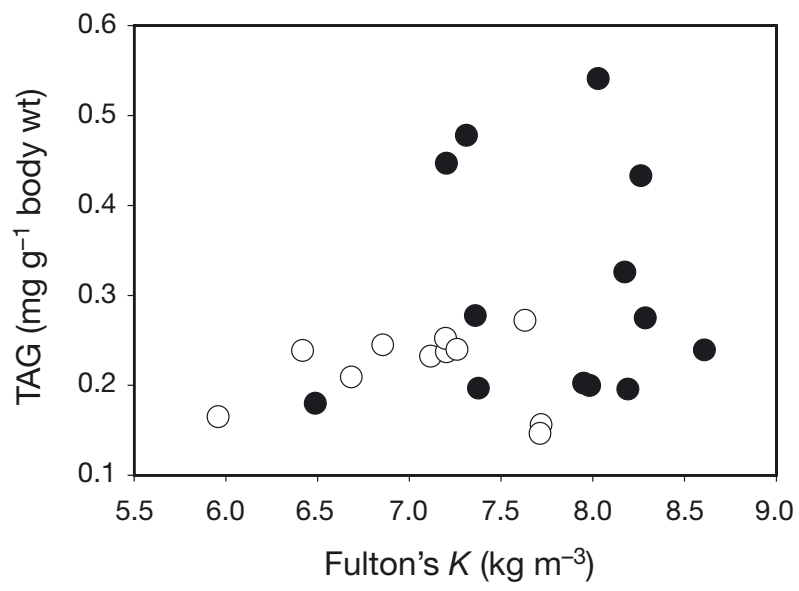

Fig. 2. Rhinogobiops nicholsii. Relationship between triacylglyceride (TAG) reserves and Fulton's $K$ for high-ration $\left(\bullet^{\prime}\right.$ $\mathrm{n}=13)$ and low-ration $(\mathrm{O} ; \mathrm{n}=11)$ fish after the $12 \mathrm{~d}$ feeding period in 2005 in 2005 to assess natural variation in lipid levels alone, fish did not differ in TAG levels among sites $\left(F_{2,4}=\right.$ 0.535, $\mathrm{p}=0.622$ ), but did differ among sampling dates $\left(F_{2,4}=13.679, \mathrm{p}=0.016\right)$.

\section{Effects of condition and refuge availability on survival}

We did not find any marked emigrants on the reef adjacent to experimental plots during surveys conducted concurrently with Expts 1 and 2. Three marked emigrants were found on adjacent plots, but this was a small fraction of the total numbers of fish placed in the field ( $\mathrm{n}=312$ ), allowing us to conclude that the losses observed were due primarily to predator-induced mortality and not emigration.

In the initial field experiment to assess the implications of condition for survival on standardized amounts of rock rubble (Expt 1), low-ration fish experienced $\sim 43 \%$ higher mortality than high-ration fish (excluding
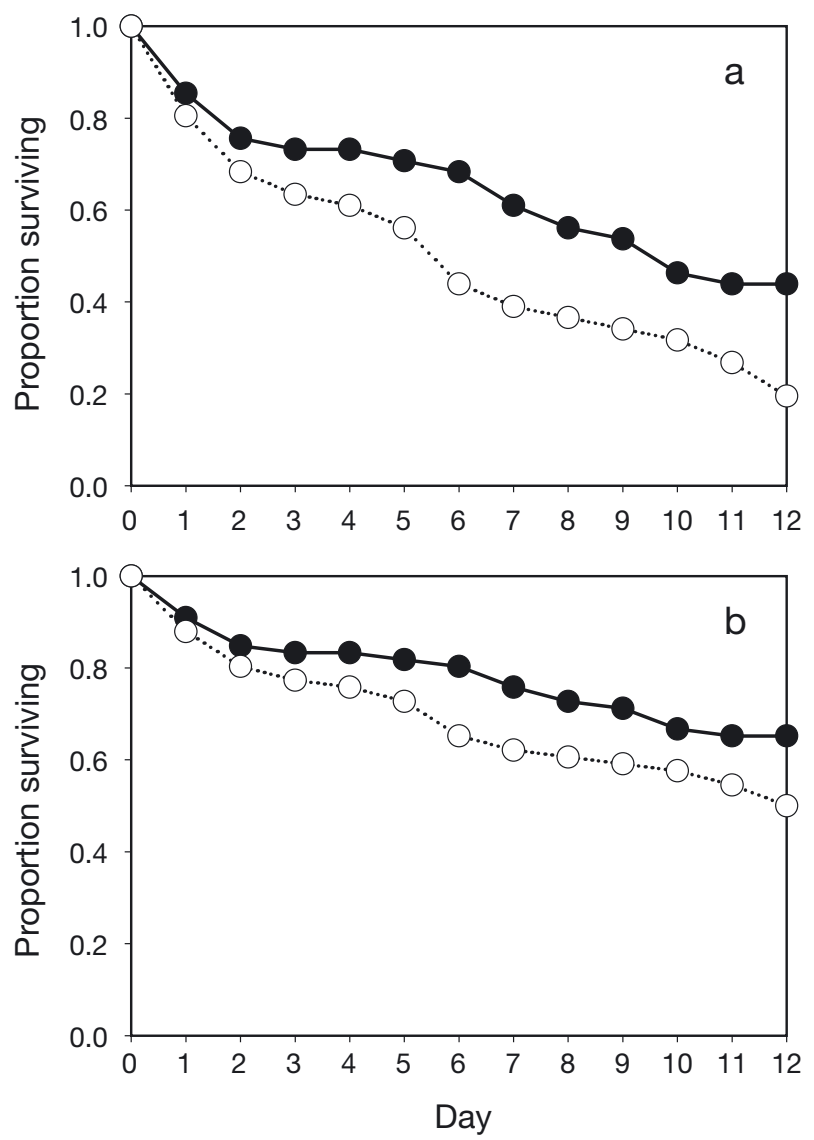

Fig. 3. Rhinogobiops nicholsii. Survival curves for recruits assigned to high-ration $(\bullet)$ and low-ration $(O)$ treatments in Expt 1: (a) excluding plots where both high- and low-ration fish survived until the end of the experiment $(n=41$ per treatment); (b) including all plots ( $\mathrm{n}=66$ per treatment) 
plots: $29 \%$ higher mean survival time for high-ration fish, $\chi^{2}=5.043, \mathrm{df}=1, \mathrm{p}=0.025$, Fig. $3 \mathrm{a}_{\text {; including all }}$ plots: $13 \%$ higher mean survival time for high-ration fish, $\chi^{2}=3.019, \mathrm{df}=1, \mathrm{p}=0.082$, Fig. 3b). Interestingly, the magnitude of the difference in survival between high- and low-ration fish was greatest in 2002 and smallest in 2005, when the high- and low-ration fish were most and least divergent with respect to Fulton's $K$, respectively. It is difficult to determine the significance of this pattern, however, due to the limited statistical power of analyses conducted for a single year.

For Expt 2, survival analyses and likelihood ratio tests revealed a significant interaction between feeding treatment and refuge availability (excluding plots: $\chi^{2}=10.132, \mathrm{df}=1, \mathrm{p}=0.001$; including all plots: $\chi^{2}=$ $8.715, \mathrm{df}=1, \mathrm{p}=0.003)$, indicating that the importance of condition for survival was dependent on refuge availability. Specifically, fish fed high rations survived longer in the field than low-ration fish on plots with moderate and high levels of refuge (excluding plots: $33 \%$ higher mean survival time for high-ration fish, $\chi^{2}=4.327, \mathrm{df}=1, \mathrm{p}=0.038$, Fig. 4a; including all plots: $15 \%$ higher mean survival time for high-ration fish, $\chi^{2}=3.159, \mathrm{df}=1, \mathrm{p}=0.076$, Fig. $4 \mathrm{~b}$ ), whereas lowration fish survived longer than high-ration fish on low-refuge plots (excluding plots: $63 \%$ higher mean survival time for low-ration fish, $\chi^{2}=4.627, \mathrm{df}=1, \mathrm{p}=$ 0.031, Fig. $4 \mathrm{a}_{\text {; }}$ including all plots: $67 \%$ higher mean survival time for low-ration fish, $\chi^{2}=3.579, \mathrm{df}=1, \mathrm{p}=$ 0.059, Fig. 4b). Further inspection of the survival curves of the 4 treatment groups together revealed that the mortality rate for high-ration fish placed on lowrefuge plots, where we observed unexpected patterns of survival, was high at the beginning of the experiment in comparison to the other treatments (Fig. 4).

\section{Condition and burst swimming speed}

In Expt 3, there was no difference in maximum burst swimming speed (measured in $\mathrm{cm} \mathrm{s}^{-1}$ ) between highand low-ration fish after the $15 \mathrm{~d}$ feeding period $\left(F_{1,53}=\right.$ $0.0001, p=0.987$ ), and no relationship between burst swimming speed and body size $\left(F_{1,53}=0.0001, \mathrm{p}=\right.$ $0.990 ;$ Fig. 5). Identical analyses using SL s${ }^{-1}$ as the unit for burst swimming speed provided analogous results (ration: $F_{1,53}=0.000, \mathrm{p}=0.988$; body size: $F_{1,53}=0.000$, $\mathrm{p}=0.987)$.

\section{DISCUSSION}

Our results demonstrate that condition is important for survival of the blackeye goby, but they also reveal a surprising interaction between condition and refuge
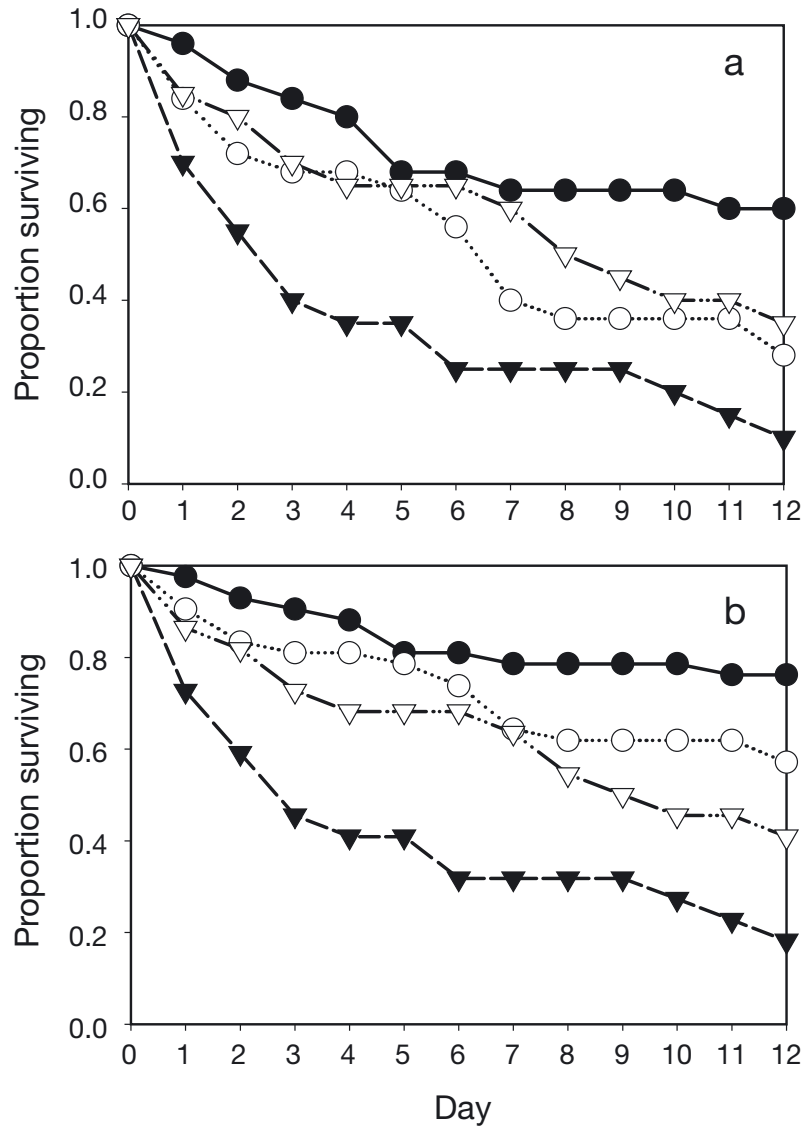

Fig. 4. Rhinogobiops nicholsii. Survival curves for recruits assigned to all 4 combinations of 2 feeding treatments and 2 refuge treatments in Expt 2: (a) excluding plots where both high- and low-ration fish survived until the end of the experiment ( $\mathrm{n}=20$ and 25 for low- and medium/high-refuge plots, respectively); (b) including all plots $(\mathrm{n}=22$ and 42 for low- and medium/high-refuge, respectively; $\bullet=$ high-ration, medium/high-refuge; $O=$ low-ration, medium/high-refuge; $\boldsymbol{\nabla}=$ high-ration, low-refuge; $\nabla=$ low-ration, low-refuge)

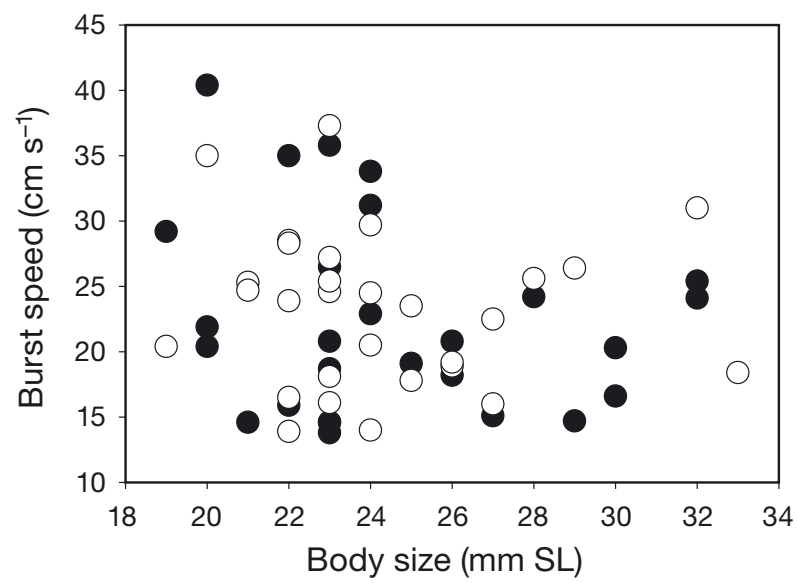

Fig. 5. Rhinogobiops nicholsii. Relationship between body size and maximum burst swimming speed for high-ration $(\mathbf{n}=$ 27 ) and low-ration $(O ; n=29)$ fish used in Expt 3 conducted in 2002. SL: standard length 
availability, providing information critical for understanding how population processes and individual performance may influence demography. Moreover, an overall reduction in the probability of mortality resulted in an unanticipated dampening of the importance of condition for survival. By documenting changes in the strength, and in some cases the direction, of selective mortality with refuge availability and predation rates, we provide a potential explanation for conflicting results produced by studies conducted in different systems or during different time periods (McCormick \& Kerrigan 1996).

Differences in condition between high- and lowration fish were reflected in each of the condition indices calculated (i.e. Fulton's $K$, lipid content), and these differences had significant implications for predation risk. Fish fed high rations experienced significantly lower mortality in the field than fish fed low rations when exposed to predators on habitat with relatively high levels of refuge. Because variation in Fulton's $K$ and levels of TAG reserves in wild fish were higher than the variation in condition of fish used in our experiments, nutritional condition may play a more important role in the survival and recruitment success of the blackeye goby than the present study would suggest. Moreover, by measuring condition and TAG reserves after settlement of fish, we may have underestimated even higher variation in energy reserves at settlement and thus the importance of condition for the demography of this population (Hoey \& McCormick 2004).

Interestingly, changes in Fulton's $K$ do not necessarily coincide with more direct measures of energy reserves such as TAG. In the present study, it is possible that the greater difference between high- and lowration fish for Fulton's $K$ than for TAG reserves was due to the limited sample size obtained for TAG relative to that for Fulton's $K$. In some species, however, the lack of correspondence between indices such as Fulton's $K$ and TAG has been attributed to rapid somatic growth in response to increased food availability, which would preclude the accumulation of lipids (Suthers et al. 1992). This provides a potential explanation for the greater difference between high- and lowration fish for Fulton's $K$ than for TAG reserves in the present study, and is supported by the fact that specific growth rates of high- and low-ration fish showed a similar pattern to that of Fulton's $K$ in the present study (E. Y. Floyd unpubl. data). It is important to note that Fulton's $K$, which is essentially a weight:length ratio, can change ontogenetically due to changes in morphology. Marine fishes tend to retain their slender larval morphology for a period after settlement before transitioning to their more robust, juvenile morphology. Consequently, it is possible that differences in Fulton's
$K$ observed in the present study are due in part to variation in developmental rates, which may have been retarded in the low-ration fish, and not only to differences in condition or 'healthiness' of the fish. Although differences in development may have been responsible in part for the dramatic differences in Fulton's $K$ between treatments, the fact that Fulton's $K$ and TAG reserves followed the same general pattern in the present study, despite the limited sample size available for TAG analyses, indicates that energy reserves play an important role in determining post-settlement survival of the blackeye goby.

Previous studies have provided extensive evidence of condition-dependent survival in tropical reef fishes (Searcy \& Sponaugle 2001, McCormick 2003, Hoey \& McCormick 2004). Although studies conducted in temperate systems are more limited, laboratory, observational, and correlative approaches from the temperatefish literature have documented relationships between food availability and recruitment (Cushing 1990, Beaugrand et al. 2003), and between larval condition (e.g. TAG reserves, growth rates, larval duration) and larval and juvenile survival (Shima \& Findlay 2002, Berkeley et al. 2004). Our results, taken together with previous work from temperate systems, demonstrate that condition is important in determining survival in temperate fishes.

The possible mechanisms linking nutritional condition to the survival of fishes include improved swimming abilities (and thus enhanced predator avoidance) of fish in good condition (Martinez et al. 2004, Skajaa et al. 2004) and increased risk-prone behavior of fish in poor condition (Skajaa et al. 2004). Improved swimming ability may be observed in well-fed fish due to increased stored energy reserves to allocate to predator avoidance in the form of muscle glycogen, important for burst-swimming and escape responses (Mommsen 2001, Martinez et al. 2004). Risk-prone behavior may become more frequent in fish fed low rations because, with their lower levels of energy reserves, they may take greater risks moving out of shelter to access food (Lima and Dill 1990, Skajaa et al. 2004, GrorudColvert \& Sponaugle 2006). In the present study, highand low-ration fish did not differ with respect to maximum burst swimming speed, suggesting that increased risk-taking behavior may be responsible for higher mortality observed in low-ration fish at relatively high levels of refuge. Although lipid analyses indicated that our high- and low-ration treatments established distinct levels of lipid reserves, glycogen and white muscle energy reserves, which are primary sources of energy used to fuel burst swimming responses, may be maintained during periods of food deprivation (Kieffer \& Tufts 1998). Maintenance of these reserves would be expected in species such as 
the blackeye goby, which rely predominantly on burst swimming responses to avoid predators. Consequently, a difference in risk-prone behavior associated with lipid reserves appears to be the most likely mechanism to explain differential survival on our experimental plots.

Although our experiments indicate that superior nutritional condition confers survival advantages to recently settled recruits, they also suggest that the importance of nutritional condition is highly dependent upon refuge availability. The higher rate of mortality of high-condition fish on low-refuge plots, and the fact that the mortality rate of these fish was high in the initial stages of the experiment in comparison to the other 3 condition-by-refuge availability treatments, indicates that their mortality may not be explained merely by a constant mortality rate due to predation. It is possible that high-ration individuals behave differently in low-refuge environments than in high-refuge environments, and these behaviors significantly increase their susceptibility to predation.

Specifically, the high-ration fish on low-refuge plots may have undertaken risky behavior in moving farther from experimental plots in search of more suitable habitat because they possessed the energy reserves necessary for this type of movement. Although fish with low levels of energy reserves have been shown to take greater risks in foraging (Grorud-Colvert \& Sponaugle 2006), they may not have taken the risk to search for a new habitat due to a lack of energy reserves required to travel potentially long distances. By performing risky, exploratory behavior at the edge of the low-refuge plots (Larsen \& Boutin 1994), the highration fish may have increased their susceptibility to predation dramatically. Conversely, the high-ration fish would have had no impetus to perform such risky behavior when refuge was abundant. Interestingly, the low-ration fish exhibited similar mortality rates on lowand high-refuge plots, suggesting that their behaviors, and consequently their risk of predation, were based not on the level of refuge, but on their condition.

Mobile animals frequently choose among habitats that differ with respect to their energetic return rate and mortality risk to the forager (Mittelbach 1981, Werner et al. 1983a,b, Gilliam \& Fraser 1987). Studies suggest that a mobile individual weighs the costs and benefits of each habitat patch (Werner et al. 1983a,b), and will ultimately make use of the habitat with the lowest ratio of mortality rate to gross foraging rate (Gilliam \& Fraser 1987). Because recruits of the blackeye goby typically consume zooplankton, it is unlikely that food availability would differ dramatically among habitats with different levels of refuge. Additionally, the high-ration fish would be better able to use available food resources when in close proximity to abun- dant refuge (Werner et al. 1983b). Thus, the highration fish would likely minimize the ratio of mortality rate to energetic uptake by moving to habitat patches with relatively high levels of refuge. Recent evidence that marine fish emigrate from small habitat patches characterized by limited cover after settlement (Ritter 2008), and of greater dispersal of individuals characterized by good body condition than those in poor condition in a variety of taxa (mammals: O'Riain et al. 1996, reptiles: Lena et al. 1998, birds: Barbraud et al. 2003), provides additional support for this scenario. Together, these studies suggest that unsuccessful emigration is a likely explanation for the elevated mortality rates of high-ration fish on low-refuge plots in the present study.

Another possible explanation for the higher mortality rate of high-ration fish on low-refuge plots is that predators actively targeted fish with higher levels of energy reserves due to their greater visibility and/or higher energy reward (Pepin et al. 1992). The highration fish may have been more visible due to their relatively robust morphology, or if they were more active than the low-ration fish (Sogard \& Olla 1996). Although the high-ration fish would also be more conspicuous on high-refuge plots, their close proximity to shelter (i.e. reduced propensity to engage in risk-prone foraging further from shelter relative to low-ration fish) may have allowed them to escape targeted attacks by predators.

The lack of mortality on a number of our experimental plots obscured the importance of condition on plots where mortality was observed to some degree, suggesting that predation rates in the system in question may play a role in determining the overall importance of condition for survival. Predation on fish used in the present study appeared to be particularly low during the first part of the summer in 2004, potentially due to a dramatic pulse of settlement of blackeye gobies that occurred at that time. The correspondence between this recruitment pulse and low predation rates suggests that the lack of predation documented during many of our trials was due to the absence of predator attacks on experimental plots, as opposed to the occurrence of unsuccessful predation attempts on both highand low-ration fish (i.e. equal vulnerability of highand low-ration fish). By assessing the importance of condition and refuge both with and without plots on which both fish survived, we can begin to understand how changing environmental conditions, including predator and recruit densities as well as refuge availability, may influence the results of similar studies in different ecosystems.

Interactions between individual performance and variation in environmental conditions or biological factors are poorly understood, but several recent studies 
reflect the increasing interest in this area of research. For example, the growth of juvenile barnacles reveals an interaction between energy reserves and environmental conditions (habitats with varying levels of food availability), whereby juveniles obtained from cyprid larvae with the lowest energy reserves grew larger at sites with abundant and high-quality food than their siblings at other sites (Thiyagarajan et al. 2005). Several studies have also documented the interactive effects of nutritional condition and environmental conditions in marine fishes. Compiled data on the early life-history traits of the bluehead wrasse Thalassoma bifasciatum at Barbados and the upper Florida Keys reveal that the degree to which mortality of juveniles is selective is dependent on variability in water temperature, with greater selectivity for nutritional condition in areas with the coldest, potentially most stressful water temperatures (Sponaugle \& Grorud-Colvert 2006). Similarly, temperature and developmental stage determine the intensity of selective mortality, based on condition, for tropical damselfish embryos and larvae (Gagliano et al. 2007); in this case, greater selectivity occurred at an intermediate temperature. Two recent studies indicate that the intensity of post-settlement selective mortality may depend upon larval history. Specifically, these studies demonstrated that selection was greater for fish that had developed near shore as opposed to offshore, suggesting that the larval environment of near-shore fish was less selectively intense (Hamilton 2008, Hamilton et al. 2008). Studies have also documented interactions between condition and biological factors, such as population densities of competitors and conspecifics. The condition and local population density of recruits of the bicolor damselfish Stegastes partitus interact to determine their growth and survival (Johnson 2008); here, higher population density reduced growth only in the high-condition treatment, but had a greater impact on survival than condition. Unlike Johnson (2008), who found that condition and population density had independent effects on survival, Figueira et al. (2008) documented an interaction between the condition of the lemon damselfish Pomacentrus moluccensis and the presence of its damselfish competitor, where condition-based selective mortality was stronger when competitors were present.

These studies and our results suggest that interactions between nutritional status and environmental conditions are not uncommon, and that patterns of survival observed under particular environmental conditions may not predict those observed under other conditions. The unpredictable nature of these survival patterns underscores the importance of evaluating the effects of nutritional condition under a variety of naturally occurring environmental scenarios. The present study indicates that both condition and refuge availability play a role in the population dynamics of fishes, and that other environmental factors, such as predation and larval settlement rates, may be critical in determining the importance of condition and refuge for survival. Considering the complex nature of these population-level processes, further studies of the interactions between nutritional condition and environmental conditions are necessary for a better understanding of the role of individual performance in population processes. Determining the prevalence and nature of these interactions in natural systems, and whether relationships between individual performance and environmental variation have long-term ecological consequences for fish populations (Jones \& McCormick 2002), will provide important insights into the processes influencing population demography.

Acknowledgements. We thank K. A. Miller, L. Garske, R. Phelps, and T. Michaels at the Wrigley Marine Science Center for making this study possible, and J. Craig, M. Atcheson, S. Sharfi, and I. Culbertson for their assistance in the lab and field. We also thank D. Deutschman for statistical advice, J. Cech for reviewing the manuscript, and 3 anonymous reviewers for their comments. We are grateful to B. MacFarlane and J. Harding at the Southwest Fisheries Science Center (NOAA Fisheries Service), Santa Cruz, California, for training in techniques used for lipid analyses. This study was in partial fulfillment of the requirements for a doctoral degree at San Diego State University and the University of California, Davis. Funding for this project was provided to E.Y.F. by the Achievement Rewards for College Scientists (ARCS) Foundation and the Joint-Doctoral Program in Ecology at San Diego State University and the University of California, Davis. Additional support was provided by grants to T.W.A. from the National Science Foundation (OCE-03-31895), the National Undersea Research Program, West Coast and Polar Regions Center (UAF(CA)-03-02), and the National Institute for Undersea Science and Technology (05-07-006). This is Contribution No. 245 of the Wrigley Institute for Environmental Studies. The experiments described herein were conducted in accordance with institutional, national, and international guidelines concerning the use of animals in research.

\section{LITERATURE CITED}

Anderson TW (2001) Predator responses, prey refuges, and density-dependent mortality of a marine fish. Ecology 82: 245-257

Barbraud C, Johnson AR, Bertault G (2003) Phenotypic correlates of post-fledgling dispersal in a population of greater flamingos: the importance of body condition. J Anim Ecol 72:246-257

Beaugrand G, Brander KM, Lindley JA, Souissi S, Reid PC (2003) Plankton effect on cod recruitment in the North Sea. Nature 426:661-664

Berkeley SA, Chapman C, Sogard SM (2004) Maternal age as a determinant of larval growth and survival in a marine fish, Sebastes melanops. Ecology 85:1258-1264

> Bligh EG, Dyer WJ (1959) A rapid method of total lipid extraction and purification. Can J Biochem Physiol 37:911-917 
Booth DJ, Beretta GA (2004) Influence of recruit condition on food competition and predation risk in a coral reef fish. Oecologia 140:289-294

Booth DJ, Hixon MA (1999) Food ration and condition affect early survival of the coral reef damselfish, Stegastes partitus. Oecologia 121:364-368

Chick JH, Van Den Avyle MJ (2000) Effects of feeding ration on larval swimming speed and responsiveness to predator attacks: implications for cohort survival. Can J Fish Aquat Sci 57:106-115

Cushing DH (1990) Plankton production and year-class strength in fish populations: an update of the match/mismatch hypothesis. Adv Mar Biol 26:249-293

Doherty PJ (2002) Variable replenishment and the dynamics of reef fish populations. In: Sale PF (ed) Coral reef fishes: dynamics and diversity in a complex ecosystem. Academic Press, San Diego, CA, p 327-355

Figueira WF, Booth DJ, Gregson MA (2008) Selective mortality of a coral reef damselfish: role of predator-competitor synergisms. Oecologia 156:215-226

- Gagliano M, McCormick MI, Meekan MG (2007) Temperature-induced shifts in selective pressure at a critical developmental transition. Oecologia 152:219-225

Gilliam JF, Fraser DF (1987) Habitat selection under predation hazard: test of a model with foraging minnows. Ecology 68:1856-1862

Grorud-Colvert K, Sponaugle S (2006) Influence of condition on behavior and survival potential of a newly settled coral reef fish, the bluehead wrasse Thalassoma bifasciatum. Mar Ecol Prog Ser 327:279-288

Hamilton SL (2008) Larval history influences post-metamorphic condition in a coral-reef fish. Oecologia 158:449-461

Hamilton SL, Regetz J, Warner RR (2008) Postsettlement survival linked to larval life in a marine fish. Proc Natl Acad Sci USA 105:1561-1566

Hentschel BT, Emlet RB (2000) Metamorphosis of barnacle nauplii: effects of food variability and a comparison with amphibian models. Ecology 81:3495-3508

Hixon MA, Webster MS (2002) Density dependence in reef fish populations. In: Sale PF (ed) Coral reef fishes: dynamics and diversity in a complex ecosystem. Academic Press, San Diego, CA, p 303-325

> Hoey AS, McCormick MI (2004) Selective predation for low body condition at the larval-juvenile transition of a coral reef fish. Oecologia 139:23-29

Johnson DW (2007) Habitat complexity modifies post-settlement mortality and recruitment dynamics of a marine fish. Ecology 88:1716-1725

Johnson DW (2008) Combined effects of condition and density on post-settlement survival and growth of a marine fish. Oecologia 155:43-52

Jones GP, McCormick MI (2002) Numerical and energetic processes in the ecology of coral reef fishes. In: Sale PF (ed) Coral reef fishes: dynamics and diversity in a complex ecosystem. Academic Press, San Diego, CA, p 221-238

Kerrigan BA (1996) Temporal patterns in size and condition at settlement in two tropical reef fishes (Pomacentridae: Pomacentrus amboinensis and $P$. nagasakiensis). Mar Ecol Prog Ser 135:27-41

Kieffer JD, Tufts BL (1998) Effects of food deprivation on white muscle energy reserves in rainbow trout (Oncorhynchus mykiss): the relationships with body size and temperature. Fish Physiol Biochem 19:239-245

- Larsen KW, Boutin S (1994) Movements, survival, and settlement of red squirrel (Tamiasciurus hudsonicus) offspring. Ecology 75:214-223

Lena JP, Clobert J, de Fraipont M, Lecomte J, Guyot G (1998)
The relative influence of density and kinship on dispersal in the common lizard. Behav Ecol 9:500-507

Lima SL, Dill LM (1990) Behavioral decisions made under the risk of predation: a review and prospectus. Can J Zool 68: 619-640

MacFarlane RB, Norton EC (1999) Nutritional dynamics during embryonic development in the viviparous genus Sebastes and their application to the assessment of reproductive status. Fish Bull 97:273-281

MacFarlane RB, Norton EC, Bowers MJ (1993) Lipid dynamics in relation to the annual reproductive cycle in yellowtail rockfish (Sebastes flavidus). Can J Fish Aquat Sci 50: 391-401

- Malone JC, Forrester GE, Steele MA (1999) Effects of subcutaneous microtags on the growth, survival, and vulnerability to predation of small reef fishes. J Exp Mar Biol Ecol 237:243-253

- Martinez M, Bedard M, Dutil JD, Guderley H (2004) Does condition of Atlantic cod (Gadus morhua) have a greater impact upon swimming performance at $U_{\text {crit }}$ or sprint speeds? J Exp Biol 207:2979-2990

McCormick MI (2003) Consumption of coral propagules after mass spawning enhances larval quality of damselfish through maternal effects. Oecologia 136:37-45

$>$ McCormick MI, Kerrigan BA (1996) Predation and its influence on the condition of a newly settled tropical demersal fish. Mar Freshw Res 47:557-562

McCormick MI, Molony BW (1992) Effects of feeding history on the growth characteristics of a reef fish at settlement. Mar Biol 114:165-173

McCormick MI, Molony BW (1993) Quality of the reef fish Upeneus tragula (Mullidae) at settlement: is size a good indicator of condition? Mar Ecol Prog Ser 98:45-54

Mittelbach GG (1981) Foraging efficiency and body size: a study of optimal diet and habitat use by bluegills. Ecology 62:1370-1386

Mommsen TP (2001) Paradigms of growth in fish. Comp Biochem Physiol B 129:207-219

O'Riain MJ, Jarvis JUM, Faulkes CG (1996) A dispersive morph in the naked mole-rat. Nature 380:619-621

> Pepin P, Shears TH, de Lafontaine Y (1992) Significance of body size to the interaction between a larval fish (Mallotus villosus) and a vertebrate predator (Gasterosteus aculeatus). Mar Ecol Prog Ser 81:1-12

- Perez C, Velando A, Dominguez J (2006) Parental food conditions affect sex-specific embryo mortality in the yellowlegged gull (Larus michahellis). J Ornithol 147:513-519

- Ritter AF (2008) Habitat variation influences movement rates and population structure of an intertidal fish. Oecologia 157:429-439

Rosner B (2006) Fundamentals of biostatistics, 6th edn. Duxbury Press, Belmont, CA

Searcy SP, Sponaugle S (2001) Selective mortality during the larval-juvenile transition in two coral reef fishes. Ecology 82:2452-2470

Sherwani FA, Parwez I (2000) Effects of stress and food deprivation on catfish, Heteropneustes fossilis (Bloch). Indian J Exp Biol 38:379-384

Shima JS, Findlay AM (2002) Pelagic larval growth rate impacts benthic settlement and survival of a temperate reef fish. Mar Ecol Prog Ser 235:303-309

> Skajaa K, Ferno A, Folkvord A (2004) Ontogenetic- and condition-related effects of starvation on responsiveness in herring larvae (Clupea harengus L.) during repeated attacks by a model predator. J Exp Mar Biol Ecol 312: 253-269

Sogard SM, Olla BL (1996) Food deprivation affects vertical 
distribution and activity of a marine fish in a thermal gradient: potential energy-conserving mechanisms. Mar Ecol Prog Ser 133:43-55

Sponaugle S, Grorud-Colvert K (2006) Environmental variability, early life-history traits, and survival of new coral reef fish recruits. Integr Comp Biol 46:623-633

Steele MA (1999) Effects of shelter and predators on reef fishes. J Exp Mar Biol Ecol 233:65-79

Steele MA, Anderson TW (2006) Predation. In: Allen LG, Pondella II DJ, Horn MH (eds) Ecology of marine fishes: California and adjacent waters. University of California Press, Berkeley, CA, p 428-448

Stobutzki IC (1997) Energetic cost of sustained swimming in the late pelagic stages of reef fishes. Mar Ecol Prog Ser 152:249-259

Suthers IM, Fraser A, Frank KT (1992) Comparison of lipid,

Editorial responsibility: Nicholas Tolimieri,

Seattle, Washington, USA otolith and morphometric condition indices of pelagic juvenile cod Gadus morhua from the Canadian Atlantic. Mar Ecol Prog Ser 84:31-40

> Thiyagarajan V, Hung OS, Chiu JMY, Wu RSS, Qian PY (2005) Growth and survival of juvenile barnacle Balanus amphitrite: interactive effects of cyprid energy reserve and habitat. Mar Ecol Prog Ser 299:229-237

Werner EE, Mittelbach GG, Hall DJ, Gilliam JF (1983a) Experimental tests of optimal habitat use in fish: the role of relative habitat profitability. Ecology 64:1525-1539

> Werner EE, Gilliam JF, Hall DJ, Mittelbach GG (1983b) An experimental test of the effects of predation risk on habitat use in fish. Ecology 64:1540-1548

Yin MC, Blaxter JHS (1987) Escape speeds of marine fish larvae during early development and starvation. Mar Biol 96: $459-468$

Submitted: December 12, 2009; Accepted: February 26, 2010 Proofs received from author(s): May 2, 2010 